\title{
Influence of the dissolution medium type on the release of diclofenac sodium and papaverine hydrochloride from granules and tablets
}

\author{
REgINA KASPEREK ${ }^{*}$, MAGDALENA NALEŚNIAK, KAROL IWANIAK, EWA POLESZAK
}

Chair and Department of Applied Pharmacy, Medical University of Lublin, Poland

\begin{abstract}
The release studies of diclofenac sodium (DIC) and papaverine hydrochloride (PAP) from composed granules and tablets into the dissolution media at different $\mathrm{pH}$ using the flow-through cell apparatus were carried out. The solubilities of these active substances vary and depend on the $\mathrm{pH}$ of a dissolution medium which confirmed the outcomes of the release studies on granules and tablets containing only one substance DIC or PAP. The most effective dissolution medium for the carried out release study of DIC and $\mathrm{PAP}$ from composed solid dosage form as granules or tablets was citrate buffer at $\mathrm{pH}$ 6.5.
\end{abstract}

Keywords: Diclofenac sodium, papaverine hydrochloride, release study, dissolution media

\section{INTRODUCTION}

Diclofenac sodium \{sodium 2-[(2,6-dichlorophenyl)amino]phenyl-acetate $\}$ is a potent non-steroidal anti-inflammatory drug (NSAID) with pronounced analgesic and antipyretic properties $[13,18,19,20]$. For improvement of the therapeutic effect and decrease the adverse effects of diclofenac sodium, the composed pharmaceutical preparations containing misoprostol, lidocaine hydrochloride, escin, tribenosine and gentamicin sulphate were produced $[18,19]$. For increased analgesic effect, the granules and tablets designed for oral administration and containing diclofenac sodium and papaverine hydrochloride in one preparation were manufactured and patented $[6,8]$. However, choosing the dissolution medium for testing in the release study on these preparations was a problem, because the solubilities of these active substances vary $[10,13,14,23,26]$. In vitro studies, such as the release study, can be used to predict in vivo release profiles and indicate the expected in vivo behaviour [23].

The solubility of diclofenac sodium depends on $\mathrm{pH}$, ionic strength and composition of the aqueous medium [10]. A salt of a weak acid, diclofenac sodium is almost in-

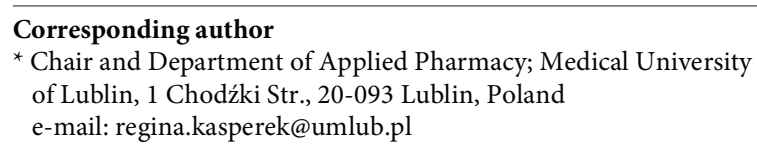

DOI: $10.12923 /$ j.2084-980X/26.1/ a.01 soluble in acidic $\mathrm{pH}$ of the stomach $[3,10,23,29]$, sparingly soluble in water [13], and soluble in phosphate buffer at pH $6.8[4,10,16]$. Those properties are confirmed by tests on the release of diclofenac sodium in the aqueous media with various ionic strengths, ionic compositions and $\mathrm{pH}$ in the range of 1-10 [10,29]. The solubility of papaverine hydrochloride depends on the $\mathrm{pH}$ of the medium and increases proportionally to the decrease of the $\mathrm{pH}$ of the medium in the range from 2.2 to 3.9 [14,26].

For the release studies Polish Pharmacopeia IX [20] recommended various dissolution media such as hydrochloric acid at $\mathrm{pH} 1$ or with the addition of sodium chloride at $\mathrm{pH} 1.2$ and 1.5, phosphate and acetate buffers at $\mathrm{pH} 4.5,5.5,5.8$, phosphate buffers at $\mathrm{pH} 6.8,7.2,7.5$ and artificial gastric and intestine juices.

In literature, there are reports describing the release studies of diclofenac sodium from different solid dosage forms carried out in various dissolution media, for example from tablets of prolonged release in an artificial gastric juice without pepsine at $\mathrm{pH} 1.2$, phosphate buffer at $\mathrm{pH}$ 4.5 and 8 , water, an artificial intestine juice without pancreatine at $\mathrm{pH} 6.8[1,2]$, from coated tablets in water and phosphate buffer at $\mathrm{pH} 6.8$ [12], from polymeric matrix to media at $\mathrm{pH}$ from the range of 1 to 6.8 [24] or 1 to 10 [10], in phosphate buffer at $\mathrm{pH} 6.5$ with addition of $0.2 \%$ polysorbate [11], $0.1 \mathrm{~mol} / 1 \mathrm{HCl}$ and phosphate buffer at $\mathrm{pH} 7.5$ [25] at $\mathrm{pH} 6.8$ [16], at $\mathrm{pH} 7.4$ [22], at pH 5.4 and at $\mathrm{pH} 7.4$ 
[21], from polymeric beads crosslinked glutaraldehyde in media at $\mathrm{pH} 1.2 ; 6.8 ; 7.4$ [27], nanoparticles based on Eudragit L-100 i L-100-PLGA in phosphate buffer at pH 6.8 [4].

The US Pharmacopoeia [28] recommended water as a dissolution medium for the release study of papaverine hydrochloride in tablets. Although there are reports describing this case, for the release studies of papaverine hydrochloride in matrix tablets phosphate buffer at $\mathrm{pH} 6.8$ [5] or water [15] as dissolution media were used.

There is no solid dosage form containing diclofenac sodium and papaverine hydrochloride in one preparation for oral administration, therefore there are no data on the release study of these two active substances from a composed preparation. The aim of this study was to choose the best dissolution medium which would be let us carry out the release studies of diclofenac sodium and papaverine hydrochloride from composed dosage forms such as granules and tablets.

\section{MATERIALS AND METHODS}

Substances and reagents. Diclofenac sodium (DIC) produced by Caesar and Loretz, GmbH, Hilden, Germany, papaverine hydrochloride (PAP) obtained from Galfarm PPH, Cefarm Lublin, Poland, the solution of HCL ( $1 \mathrm{~mol} / \mathrm{L})$, citric acid monohydrate, citrate sodium dihydrogen, potassium dihydrogen orthophosphate and sodium hydroxide $(1 \mathrm{~mol} / \mathrm{L})$ were all purchased from POCh Gliwice, Poland. Also, distilled water was used. All other reagents were of an analytical grade.

Solid dosage forms. Composition and preparation of the granules $(\mathrm{G})$ and tablets $(\mathrm{T})$ containing DIC and PAP were described in the patents $[6,8]$. Granules containing only one substance DIC (G-DIC) or PAP only (G-PAP), were obtained in the same manner as described in the patents $[6,8]$, but composition contained only one active substance.

Composition: One dose of granules $(\mathrm{G})$ or tablets $(\mathrm{T})$ consists of $50 \mathrm{mg}$ DIC, $20 \mathrm{mg}$ PAP and excipients to obtain $300 \mathrm{mg}$ of weight. One dose of granules (G-DIC) or tablets (T-DIC) consists of $50 \mathrm{mg}$ DIC and excipients to obtain $280 \mathrm{mg}$ of weight. One dose of granules (G-PAP) or tablets (T-PAP) consists of $20 \mathrm{mg}$ PAP and excipients to obtain $250 \mathrm{mg}$ of weight. Granules and tablets have different excipients.

Preparation. Granules (G, G-DIC, G-PAP) were prepared by wet granulation process (granulator Erweka, Germany with a $1.0 \mathrm{~mm}$ sieve). Tablets (T, T-DIC, T-PAP) were prepared by the tabletting of granules (a tablet press machine Erweka, Germany), which were previously obtained by wet granulation process.

Physical properties of the prepared granules and tablets are in compliance with pharmacopeial requirements [20]. The content of active substances are $50 \mathrm{mg}$ DIC $( \pm 5 \%)$ and $20 \mathrm{mg}$ PAP $( \pm 5 \%)$ in one tablet at $300 \mathrm{mg}$ of weight of $(\mathrm{T})$ or one dose of granules $(\mathrm{G})$ and $50 \mathrm{mg}$ DIC $( \pm 5 \%)$ in one tablet at $280 \mathrm{mg}$ of weight of (T-DIC) or one dose of granules (T-DIC) and $20 \mathrm{mg}$ PAP $( \pm 5 \%)$ in one tablet at $250 \mathrm{mg}$ of weight of (T-PAP).

Dissolution media. The dissolution media such as hydrochloric acid $0.1 \mathrm{~mol} / \mathrm{L}$, citrate buffers at $\mathrm{pH} 4.5,6.5$, 6.8 and phosphate buffers at $\mathrm{pH} 4.5,6.5,6.8$ were used.

Release study. The release test of active substances from granules and tablets was carried out at the flowthrough cell apparatus similar to pharmacopeial apparatus 4 , previously used at the release test [7], equipped with the dissolution cell with the internal diameter of $2 \mathrm{~cm}$ and internal height of $2.5 \mathrm{~cm}$ made of a transparent plastic, in which there were two glass filters at pore size $15-40 \mu \mathrm{m}$ placed on the upper and lower parts of the cell. The tablet was set horizontally on the lower glass filter in the dissolution cell. The dissolution medium was pumped at a 4.26 $\mathrm{mL} / \mathrm{min}$ flow rate by the peristaltic pump (Cole Parmer, Masterflex, USA). The apparatus was maintained at $37^{\circ} \pm$ $0.5^{\circ} \mathrm{C}$ by water heated from the thermostat (MLW, Mechanik, Medingen, Germany). The accurately weighed tablet or one dose of the granules was placed into the dissolution cell, the dissolution medium flew at an appropriate rate and $20 \mathrm{~mL}$ portions of effluents were collected and filtered using Whatmann filters. Five milliliters of each effluent was instantly diluted in $10 \mathrm{~mL}$ of methanol. Experiments were performed for six tablets and six doses of granules.

Spectrophotometric analysis. The contents of active substances and the quantity of the released DIC and PAP in the dissolution media were determined by spectrophotometric method based on simultaneous equation method published earlier [9]. The absorbances of the solutions were measured in a spectrophotometer (Spectromom 195, Hungary).

\section{RESULTS}

As shown Fig. 1a, within 70 min, 98.18\% (80\% within $8 \mathrm{~min}$ ) of DIC from (G-DIC) and $31.15 \%$ of PAP from (G-PAP) were released in water. Also, $92.02 \%$ of DIC ( $80 \%$ within $11.7 \mathrm{~min}$ ) and $62.65 \%$ of PAP were released from composed granules $(\mathrm{G})$.

Within $70 \mathrm{~min}$, only $7.36 \%$ of DIC from single granules (G-DIC) were released in acidic medium $(0.1 \mathrm{~mol} / 1$ $\mathrm{HCl}$ ) (Fig. 1b), but the release of PAP ( $80 \%$ in $6 \mathrm{~min}$ ) from (G-PAP) amounted to $92.05 \%$. Similarly, within 70 min, 3.86\% DIC and $91 \%$ PAP (80\% after $17 \mathrm{~min}$ ) were released from composed granules $(\mathrm{G})$.

DIC was completely released $(100 \%)$ in phosphate buffer at pH 6.8 (Fig. 1c) within 70 min from single granules (G-DIC) $(80 \%$ in $8 \mathrm{~min})$ and from $(\mathrm{G})$ the value reached $84.1 \%$ ( $80 \%$ in $48 \mathrm{~min})$. The release of PAP from 
(G-PAP) amounted to $9.75 \%$ and from $(\mathrm{G})$ to $51.05 \%$ PAP.
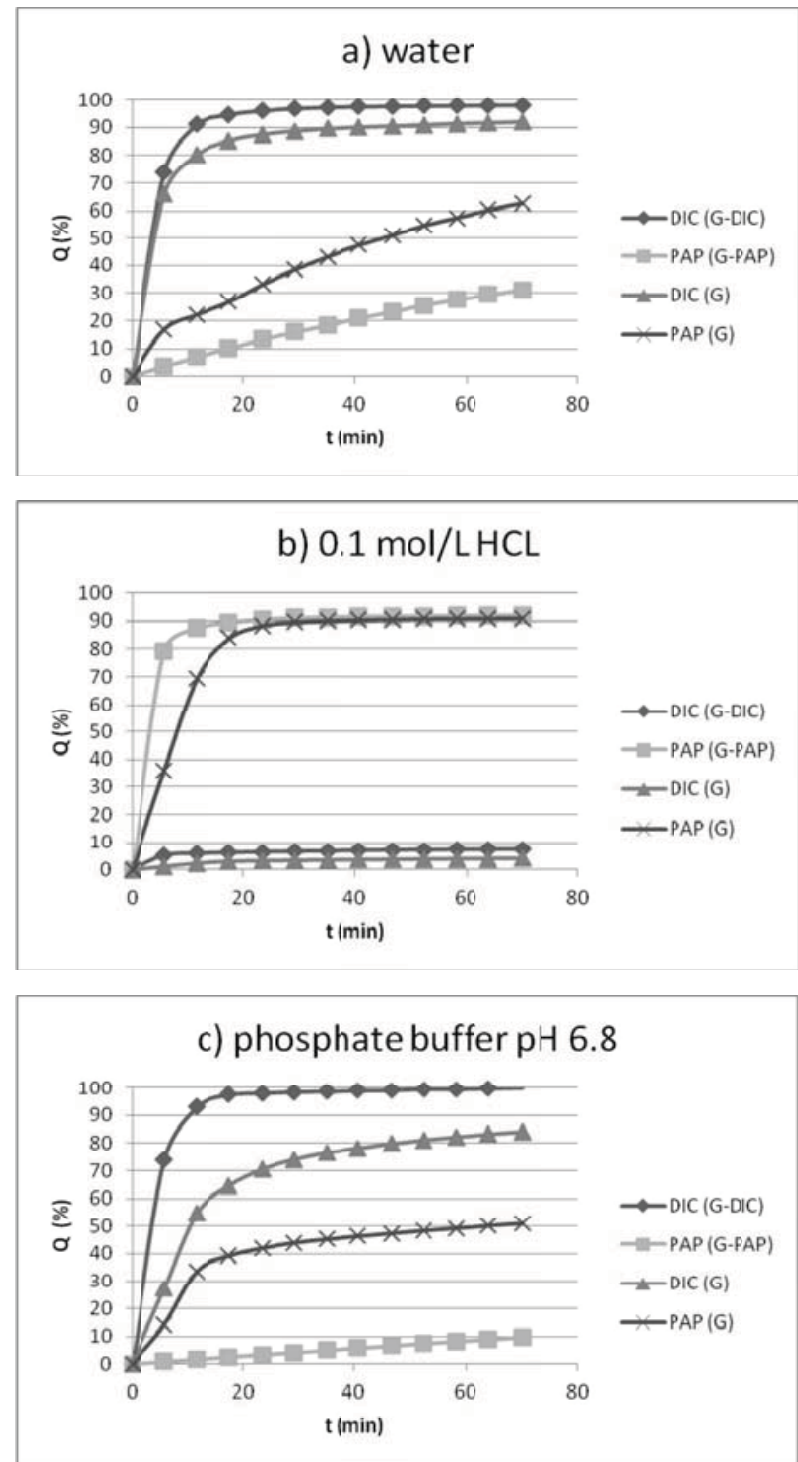

Fig. 1. Mean dissolution profiles of DIC and PAP from single and composed granules (G-DIC, G-PAP, G) at different media: a) water, b) $0.1 \mathrm{~mol} / \mathrm{L} \mathrm{HCL}, \mathrm{c})$ phosphate buffer $\mathrm{pH} 6.8$.

As shown in Fig. 2a, within 78 min, 59.64\% DIC and 95.5\% PAP were released in phosphate buffer at $\mathrm{pH} 4.5$ from single tablets (T-DIC; T-PAP) and from composed tablets (T) $54.66 \%$ DIC and 90.25\% PAP were released.

As shown in Fig. 2b, in phosphate buffer at $\mathrm{pH}$ 6.5, 93.62\% DIC from single tablets (T-DIC) and 53.09\% PAP

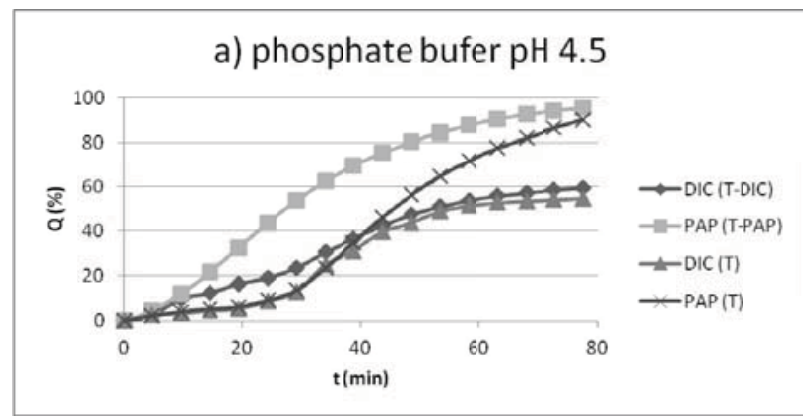

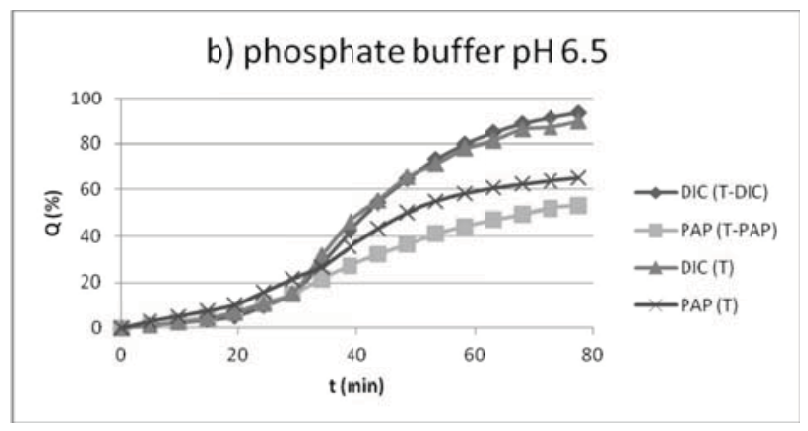
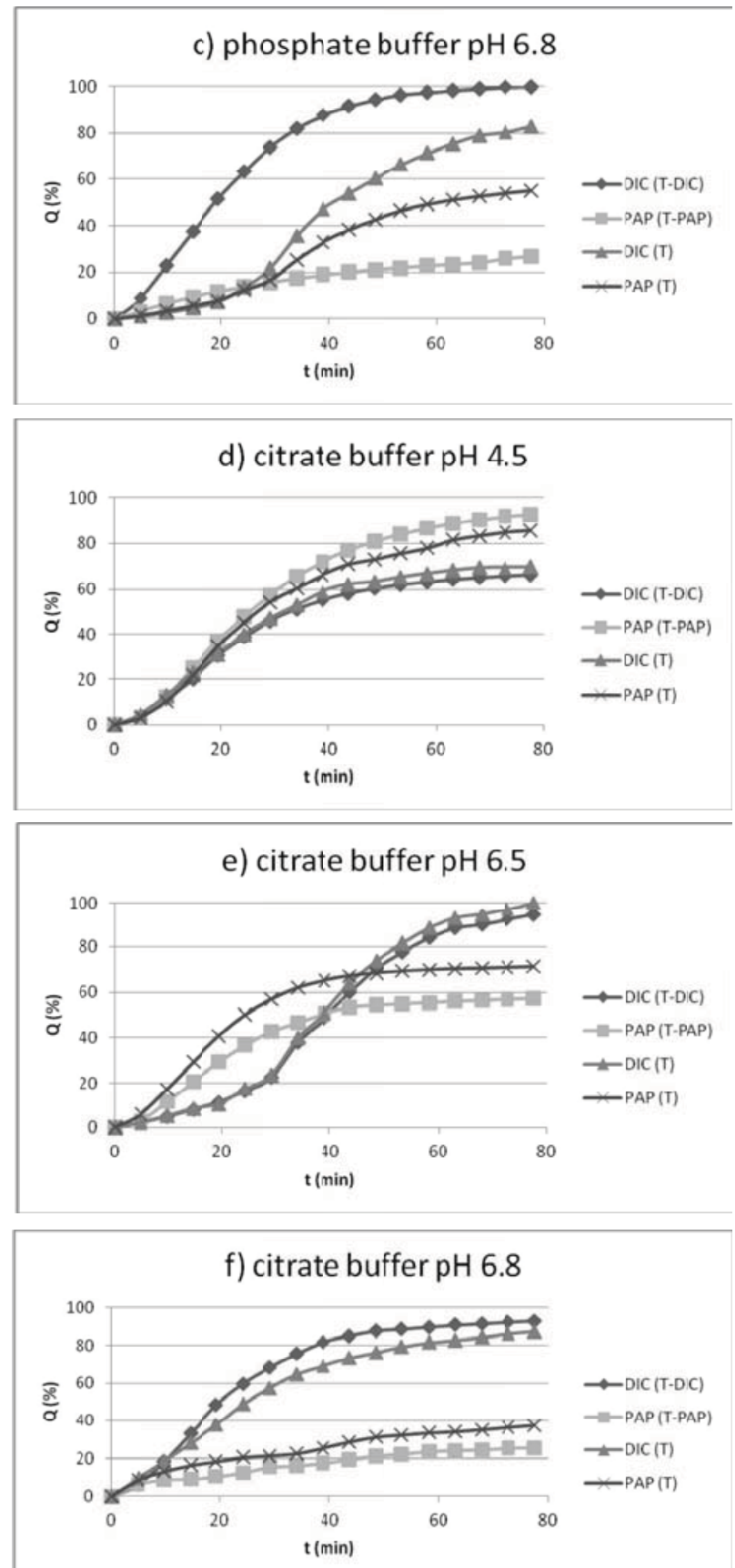

Fig. 2. Mean dissolution profiles of DIC and PAP from single and composed tablets (T-DIC, T-PAP, T) at different media: a) phosphate buffer $\mathrm{pH} 4.5, \mathrm{~b})$ phosphate buffer $\mathrm{pH}$ 6.5, c) phosphate buffer $\mathrm{pH} 6.8$, d) citrate buffer $\mathrm{pH} 4.5$, e) citrate buffer $\mathrm{pH} 6.5$, f) citrate buffer $\mathrm{pH} 6.8$.

from (T-PAP) were released, whereas the values for composed tablets amounted to $89.64 \%$ DIC and $65.24 \%$ PAP. 
In phosphate buffer at pH 6.8 (Fig. 2c), 100\% and 83\% DIC were released from (T-DIC) and (T) whereas for (T-PAP) and (T) the values amounted to $26.7 \%$ and $55 \%$ PAP, respectively.

In citrate buffer at $\mathrm{pH} 4.5$, (Fig. 2d) $66.27 \%$ and $69.7 \%$ DIC and $92.8 \%$ and $85.76 \%$ PAP were released from single and composed tablets, respectively.

With the increase of $\mathrm{pH}$ of citrate buffers the quantity of the released DIC and PAP were changing as follows: at pH 6.5 (Fig. 2e) 94.5\% and 99.87\% DIC from (T-DIC) and $(\mathrm{T})$ and $65.86 \%$ and $71.32 \%$ PAP from (T-PAP) and (T); whereas at pH 6.8 (Fig. 2f) $93.1 \%$ and $87.56 \%$ DIC, and $25.4 \%$ and $37.56 \%$ PAP from single and composed tablets were released respectively.

\section{DISCUSSION}

The results of the release study of active substances from granules in the three dissolution media such as water, $0.1 \mathrm{~mol} / \mathrm{L} \mathrm{HCl}$ and phosphate buffer at $\mathrm{pH} 6.8$ show that the quantity of the substances released from single granules (G-DIC, G-PAP) are different than from composed granules $(G)$. In acidic medium within $70 \mathrm{~min}$ about $4 \%$ DIC from (G-DIC), $98 \%$ in water and $100 \%$ in phosphate buffer at pH 6.8 were released, what confirms that diclofenac sodium is practically insoluble in hydrochloric acid at $\mathrm{pH}$ 1.1, and fairly soluble in water and in phosphate buffer at pH 6.8 [10,29]. The solubility of PAP is higher when $\mathrm{pH}$ of dissolution medium is decreased [26], which is shown by the data of PAP quantity released to $0.1 \mathrm{~mol} / 1$ $\mathrm{HCl}(92.05 \%)$, water $(31.15 \%)$ and phosphate buffer at pH 6.8 (9.75\%).

In acidic medium the presence of PAP in the composed granules $(\mathrm{G})$ did not affect the improvement of the release of DIC, whereas the presence of DIC delayed PAP release for about $11 \mathrm{~min}$, because $80 \%$ PAP was released after 6 min and 17 min from (G-PAP) and (G), respectively. The presence of DIC in water in $(\mathrm{G})$ caused a double increase in quantity of PAP released $(31.15 \%$ from G-PAP to $62.65 \%$ from $\mathrm{G}$ ), and in phosphate buffer at $\mathrm{pH} 6.8$ the presence of DIC in $(\mathrm{G})$ caused the increase of PAP release over four times $(9.75 \%$ from G-PAP to $51.05 \%$ from $\mathrm{G})$. Taking all the outcomes into account, the impact of one of the substances on solubility of the other substance in the dissolution medium can be observed.

Bertocchi et al. [2] reported that about 30\% DIC from tablets with prolonged release containing DIC in phosphate buffer at $\mathrm{pH} 4.5$ was released. In an artificial gastric juice at $\mathrm{pH} 1.2$ about $1 \%$ DIC and in an artificial intestine juice at $\mathrm{pH} 6.8,80-100 \%$ DIC were released. These data confirm that solubility of DIC depends on the $\mathrm{pH}$ of a dissolution medium.
The release studies of DIC and PAP from single granules (G-DIC; G-PAP) confirmed that DIC is practically insoluble in hydrochloric acid $0.1 \mathrm{~mol} / \mathrm{L}$ and showed that addition of PAP in composed granules (G) does not change the solubility of DIC in tested acidic medium. Nowadays water is not recommended by Polish Pharmacopea [20] to be used as a dissolution medium therefore for dissolution study of active substances from tablets phosphate and citrate buffers at different $\mathrm{pH}$ were used. In phosphate buffer at $\mathrm{pH} 4.5$ within $78 \mathrm{~min}$ about $80 \%$ PAP were released while from T-PAP it took $48 \mathrm{~min}$ and 68 min from $(\mathrm{T})$. The data show that presence of DIC in (T) caused a prolonged release time of PAP for about $20 \mathrm{~min}$. In tablets $(\mathrm{T})$ it could observed that the quantity of the released DIC decreased in about $5 \%$, which was probably caused by the presence of PAP. Within 78 min more DIC both from T-DIC and from (T) (about $6 \%$ and 15\%, respectively) in citrate buffer at $\mathrm{pH} 4.5$ were released.

Bartolomei et al. [1] reported that the release of DIC from tablets with prolonged release depended on a dissolution medium as follows: at phosphate buffers at $\mathrm{pH} 6.8$ about $70-90 \%$ in $1-2 \mathrm{~h}$, at $\mathrm{pH} 4.5$ about $1.5 \%$ in $1 \mathrm{~h}$ and $3.5 \%$ in $2 \mathrm{~h}$.

The solubility of DIC in dissolution media at $\mathrm{pH} 3$ and below 3 is low, but increased in media at $\mathrm{pH} 6.5$ and higher [10,17].

The results from the release studies in phosphate buffer at 6.8 showed that the quantity of released PAP from composed tablets was higher for about $28 \%$ and DIC was lower for about $17 \%$ than from single tablets. Bearing in mind the slight release of PAP from single tablets (T-PAP) in phosphate buffer at pH $6.8(26.7 \%)$, the release study in citrate buffer at $\mathrm{pH} 6.8$ was carried out.

The impact of phosphate buffer on citrate buffer at $\mathrm{pH}$ 6.8 did not cause the increase in the quantity of released substances from T-DIC and T-PAP, but a little decrease in the release of DIC (about 5\%) and a slight increase in the release of PAP (about 8\%). Within $78 \mathrm{~min}$, in phosphate buffer at $\mathrm{pH} 6.5$, about 94\% DIC and 53\% PAP from single tablets and $90 \%$ DIC and $65 \%$ PAP from composed tablets were released. It showed that the presence of both substances in the solution while the release caused the decrease in the quantity of the released DIC in about $4 \%$ and increased PAP in about $12 \%$. When the phosphate buffer was changed to citrate buffer at $\mathrm{pH} 6.5,95 \%$ DIC and $57 \%$ PAP from T-DIC and $100 \%$ DIC and $71 \%$ PAP T-PAP and from (T) were released, respectively. It shows that the release process carried out in citrate buffer at $\mathrm{pH}$ 6.5 was the best and runs in parallel to time for both substances. The citrate buffer at $\mathrm{pH} 6.5$ is the best dissolution medium for the carried out release study of DIC and PAP from composed solid dosage forms such as tablets. 


\section{REFERENCES:}

1. Bartolomei M. et al.: Physicochemical characterization and intrinsic dissolution studies of a new hydrate form of diclofenac sodium: comparison with anhydrous form. J. Pharm. Biomed. Anal. 40, 1105, 2006.

2. Bertocchi P. et al.: Diclofenac sodium multisource prolonged release tablets-a comparative study on the dissolution profiles. J. Pharm. Biomed. Anal. 37, 679, 2005.

3. Bravo S.A., Lamas M.C., Salamon C.J.: In vitro studies of diclofenac sodium controlled-release from biopolymeric hydrophilic matrices. J. Pharm. Pharm. Sci. 53, 213, 2002.

4. Cetin M., Atila A., Kadioglu Y.: Formulation and in vitro characterization of Eudragit L100 and Eudragit L-100PLGA nanoparticles containing diclofenac sodium. AAPS PharmSciTech. 11, 3, 1250, 2010.

5. Gabr K.E.: Effect of organic acids on the release patterns of weakly basic drugs from inert sustained release matrix tablets. Eur. J. Pharm. Biopharm. 38, 199, 1992.

6. Kasperek R.: Granulat na bazie diklofenaku sodowego i sposób jego wytwarzania. Polish Patent No P-364419, 2008.

7. Kasperek R.: Simultaneous release of diclofenac sodium and papaverine hydrochloride from tablets and pellets using the flow-through cell apparatus described by dimensionless equations. Acta Pol. Pharm. Drug Res. 68, 2, 261, 2011.

8. Kasperek R.: Tabletki na bazie diklofenaku sodowego o działaniu przeciwbólowym i spazmolitycznym oraz sposób ich wytwarzania. Polish Patent No P-380847, 2010.

9. Kasperek R. et al: Development of spectrophotometric method for simultaneous estimation of diclofenac sodium and papaverine hydrochloride in tablets based on simultaneous equation method. Curr. Issues Pharm. Med. Sci. 25, 2, $182,2012$.

10. Kincl M. et al.: Study of physicochemical parameters affecting the release of diclofenac sodium from lipophilic matrix tablets. Acta Chim. Slov. 51, 409, 2004.

11. Kiortsis S. et al.: Drug release from tabletted wet granulations comprising cellulosic (HPMC or HPC) and hydrophobic component. Eur. J. Pharm. Biopharm. 59, 73, 2005.

12. Lin S.Y., Lin K.H., Li M.J.: Micronized ethylcellulose used for designing a directly compressed time-controlled disintegration tablet. J. Controlled Release 70, 321, 2001.

13. Martindale: The complete drug reference. (2011). The Pharmaceutical Press, London.

14. Miyajima M. et al.: Factors influencing the diffusioncontrolled release of papaverine from poly (L-lactic acid) matrix. J. Controlled Release 4, 56, 85, 1998.
15. Moritz M., Łaniecki M.: Modified SBA-15 as the carrier for metoprolol and papaverine: Adsorption and release study. J. Solid State Chem. 184, 1761, 2011.

16. Mourăo S.C. et al.: Dissolution parameters for sodium diclofenac-containing hypromellose matrix tablet. Int. J. Pharm. 386, 201, 2010.

17. Palomo M., Ballesteros M., Frutos P.: Analysis of diclofenac sodium derivatives. J. Pharm. Anal. 21, 83, 1999.

18. Pharmindex. Vademecum leków. (2012). UBM Medica Poland, Warsaw.

19. Podlewski J.K., Chwalibogowska-Podlewska A. (2010). Leki współczesnej terapii. The Press of Medical Tribune Poland, Warsaw.

20. Polish Pharmacopoeia IX. (2011). Urząd Rejestracji Produktów Leczniczych, Wyrobów Medycznych i Produktów Biobójczych, PTF Warsaw, Poland.

21. Proikakis C.S., Tarantili P.A., Andreopoulos A.G.: The role of polymer/drug interactions on the sustained release from poly(DL-lactic acid) tablets. Eur. Polym. J. 42, 3269, 2006.

22. Rani M., Mishra B.: Comparative in vitro and in vivo evaluation of matrix, osmotic matrix, and osmotic pump tablets for controlled delivery of diclofenac sodium. AAPS PharmSciTech. 5, 71, 1, 2004.

23. Saleh S.I. et al.: Comparative dissolution profiles of five internationally-available sustained-release diclofenac dosage forms. S.T.P. Pharm. Sci. 2, 3, 242, 1992.

24. Samani S.M., Montaseri H., Kazemi A.: The effect of polymer blends on release profiles of diclofenac sodium from matrices. Eur. J. Pharm. Biopharm. 55: 351, 2003.

25. Savașer A., Özkan Y., Işimer A.: Preparation and in vitro evaluation of sustained release tablet formulations of diclofenac sodium. Farmaco 60, 171, 2005.

26. Serajuddin A.T.M., Rosoff M.: $\mathrm{pH}$-solubility profile of papaverine hydrochloride and its relationship to the dissolution rate of sustained-release pellets. J. Pharm. Sci. 73, 1203, 1984.

27. Şanli O., Ay N., Işiklan N.: Release characteristics of diclofenac sodium from poly(vinyl alcohol)/sodium alginate and poly(vinyl alcohol)-grafted-poly(acrylamide)/sodium alginate blend beads. Eur. J. Pharm. Biopharm. 65, 204, 2007.

28. The United States Pharmacopeia USP XXII. (1990). The United States Pharmacopeial Convention, Inc., Rockville, USA.

29. Velasco M.V. et al: Influence of drug: Hydroxypropylmethylcellulose ratio, drug and polymer particle size and compression force on the release of diclofenac sodium from HPMC tablets. J. Controlled Release 57, 75, 1999. 